\title{
Çocuklarda Konjenital İzole Penil Torsiyon ve Basit Cerrahi Onarımı
}

\section{Congenital Isolated Penile Torsion and Simple Surgical Repair in Children}

\author{
${ }^{1}$ Mehmet ARPACIK, ${ }^{1}$ Hayriye Nihan KARAMAN AYYILDIZ, ${ }^{1}$ Semih Lütfü MİRAPOĞLU, \\ ${ }^{1}$ Ceyhan ŞAHIN, ${ }^{1}$ Zekeriya İLÇE
}

${ }^{1}$ Sağlık Bilimleri Üniversitesi, Ümraniye Eğitim ve Araştırma Hastanesi, Çocuk Cerrahisi Kliniği, İstanbul, Türkiye

Mehmet Arpacik: https://orcid.org/0000-0001-7149-5627

Hayriye Nihan Karaman Ayy1ldız: https://orcid.org/0000-0003-0180-5022

Semih Lütfü Mirapoğlu: https://orcid.org/0000-0002-0112-7295

Ceyhan Şahin: https://orcid.org/0000-0003-3101-3915

Zekeriya İlçe: https://orcid.org/0000-0002-3473-5051

\section{ÖZ}

Amaç: Amacımız konjenital izole penil torsiyon prevalansını saptamak ve basit bir teknik ile onarım sonuçlarını sunmaktır.

Materyal ve Metot: Kliniğimize sünnet istemiyle 2016 ile 2019 yılları arasında başvuran 2650 erkek çocuk konjenital izole penil torsiyon açısından değerlendirildi.Torsiyon derecesi ve yönüne göre sinıflandırıldı ve klinik bulguları incelendi. Torsiyon derecesi $>45$ derece olan hastalara sünnet ve degloving uygulandı. Raphe mevcut konumunda birakılarak frenilum-cilt yeniden hizalama ile torsiyon düzeltildi. Sonuçlar değerlendirildi.

Bulgular: Çocukların \%1,2 $(\mathrm{n}=32)$ 'sinde $>45^{\circ}$ konjenita izole penil torsiyon tespit edildi. Torsiyon yönü $\% 93,8$ $(\mathrm{n}=30)$ hastada sola, \%6,2 $(\mathrm{n}=2)$ hastada sağa idi. Hastaların \%37,5 $(\mathrm{n}=12)$ 'inde peniste eğrilik, okul çağındaki üç hastada peniste eğrilik ve yana işeme şikayeti vardı. Ameliyat sonrası hastaların \%9,3 $(\mathrm{n}=3)$ 'ünda kendiliğindendüzelen ekimoz görüldü. Hiçbir hastada rezidü torsiyon görülmedi.

Sonuc: Cocuklarda $>45^{\circ}$ izole penil torsiyon oran $1 \% 1,2$ idi. Raphe mevcut konumunda birakıldığında basit ve güvenli bir yöntem olan degloving-cilt yeniden hizalama ile tüm torsiyonlar düzeltilebilir.

Anahtar Kelimeler: Cerrahi onarım, çocuk, penil torsiyon, prevelans

\section{ABSTRACT}

Objective: We aimed to determine the prevalence of congenital isolated penile torsion and to present the results of correction by a simple surgical technique.

Materials and Methods: Between 2016 and 2019, 2650 boys who presented circumcision request were evaluated in terms of congenital isolated penile torsion in our clinic. They were classified in terms of the degree and direction of torsion, and their clinical complaints were investigated. Circumcision and degloving were performed to patients that its had 45 degrees or more torsion. Raphe was left in its original position, and torsion was corrected by frenulum-skin realignment. Results were evaluated.

Results: Congenital isolated penile torsion of $>45^{\circ}$ was reported in $1.2 \%(\mathrm{n}=32)$ boys. The direction of torsion was to the left in $93.8 \%(\mathrm{n}=30)$ and to the right in $6.2 \%$ $(\mathrm{n}=2)$ patients. Moreover, $37.5 \%(\mathrm{n}=12)$ patients had complaints of torsion in the penis, and three patients of school age had complaints of sideways-pointing urine stream. Ecchymosis, which resolved itself, was observed in $9.3 \%$ $(n=3)$ of the postoperative patients. No patients had residual torsion.

Conclusion: The prevalence of congenital isolated penile torsion was in $1.2 \%\left(>45^{\circ}\right)$ boys. The method of degloving and frenulum-skin realignment leaving the raphe in its original position is a safe and simple method that can be performed to correct all torsions.

Keywords: Children, penile torsion, prevelans, surgical correction
Sorumlu Yazar / Corresponding Author:

Mehmet Arpacik

SağlıkBilimleri Üniversitesi, Ümraniye Eğitim ve Araştırma Hastanesi, Cocuk Cerrahi Kliniği, İstanbul / TURKIYE Tel: +905056178305

E-mail: mehmetarpacik@hotmail.com
Yayın Bilgisi / Article Info:

Gönderi Tarihi/ Received: 31/09/202

Kabul Tarihi/ Accepted: 21/10/2021

Online Yayın Tarihi/ Published: 01/12/2021 


\section{GíRiş}

Penil torsiyon, penisin uzun ekseni etrafindaki rotasyon anomalisidir. Hipospadias ve kordi gibi penil anomaliler ile birlikte veya izole olabilir. Konjenital veya penise uygulanan cerrahiye bağlı oluşabilir. ${ }^{1-3}$ Torsiyon derecesine göre hafif $(<45)$, 0rta $(45-90)$ ve ileri ( $>90$ ) derece olarak siniflandırılır. Torsiyon derecesi ve ek anomali varlığına göre uygulanan cerrahi yöntem değişiklik gösterir. ${ }^{4-5}$

$\mathrm{Bu}$ çalışmanın amacı; cerrahi tedavi gereken konjenital izole penil torsiyon prevelansını saptamak ve raphe'yi mevcut konumunda birakarak degloving-cilt yeniden hizalama ile penil torsiyonu düzeltiğimiz hastalarımızın sonuçlarını sunmaktır.

\section{MATERYAL VE METOT}

Sağlık Bilimleri Üniversitesi, Ümraniye Eğitim Araştırma Hastanesi Etik Kurulundan onay alınmıştır (Tarih: 20.11.2019, karar no:24428). Çalışma Dünya Tıp Birliği Birliği etik ilkelerine uygun ve hastaların ebeveyninden izin alınarak yapılmıştır.

Sağlık Bilimleri Üniversitesi, Ümraniye Eğitim Araştırma Hastanesi, Çocuk Cerrahi kliniğine sünnet istemiyle 2016 ile 2019 yılları arasında başvuran 0-8 yaş aralığında 2650 erkek çocuğun verileri değer- lendirildi. Hipospadias ve penil kordisi olan, herhangi bir sebeple penise cerrahi işlem uygulanmış, sünnet olmuş ve 45 dereceden az torsiyonu olan hastalar çalışma dışı bırakıldı. Konjenital izole penil torsiyonu 45 derecenin üstünde olan hastalar çalışmaya dahil edildi. $\mathrm{Bu}$ kriterlere uyan 32 hastanın verileri değerlendirildi. Hastaların yaşı, sünnet istemi dışında şikayetleri, torsiyonun derecesi, torsiyonun yönü, cerrahi işlem ve komplikasyonlar kaydedildi.

Cerrahi Işslem: Genel anestezi altında koronal sulkusa $5 \mathrm{~mm}$ mesafede yapılan sirküler insizyon ile sünnet derisi eksize edildi. Buck's fasyası ile cilt arasındaki fibröz yapılar kesilerek penoskrotal seviyeyekadar degloving yapıldı. Yapılan degloving ile penis aksının kısmen düzeldiği görüldü. Kalan torsiyon raphe mevcut konumunda birakılarak 5/0 rapid vicryl ile ilk sutur glanuler frenulumdan ve karşı taraf cildinden penis aksını düzeltecek şekilde geçildi. Diğer süturler İlk sutur baz alınarak çepeçevre atıldı (Resim 1).

Elastik bandaj ile pansuman yapıldı. Post operatif 2 . gün pansumanı açıldı. Ameliyattan 10 gün, 1 ve 3 ay ile 1 y1l sonra değerlendirildi. Kanama, hematom ve enfeksiyon erken komplikasyon olarak değerlendirildi. Üçüncü ay takibinden sonra 15 derecenin üstünde penil torsiyonu olanlar nüks olarak değer-
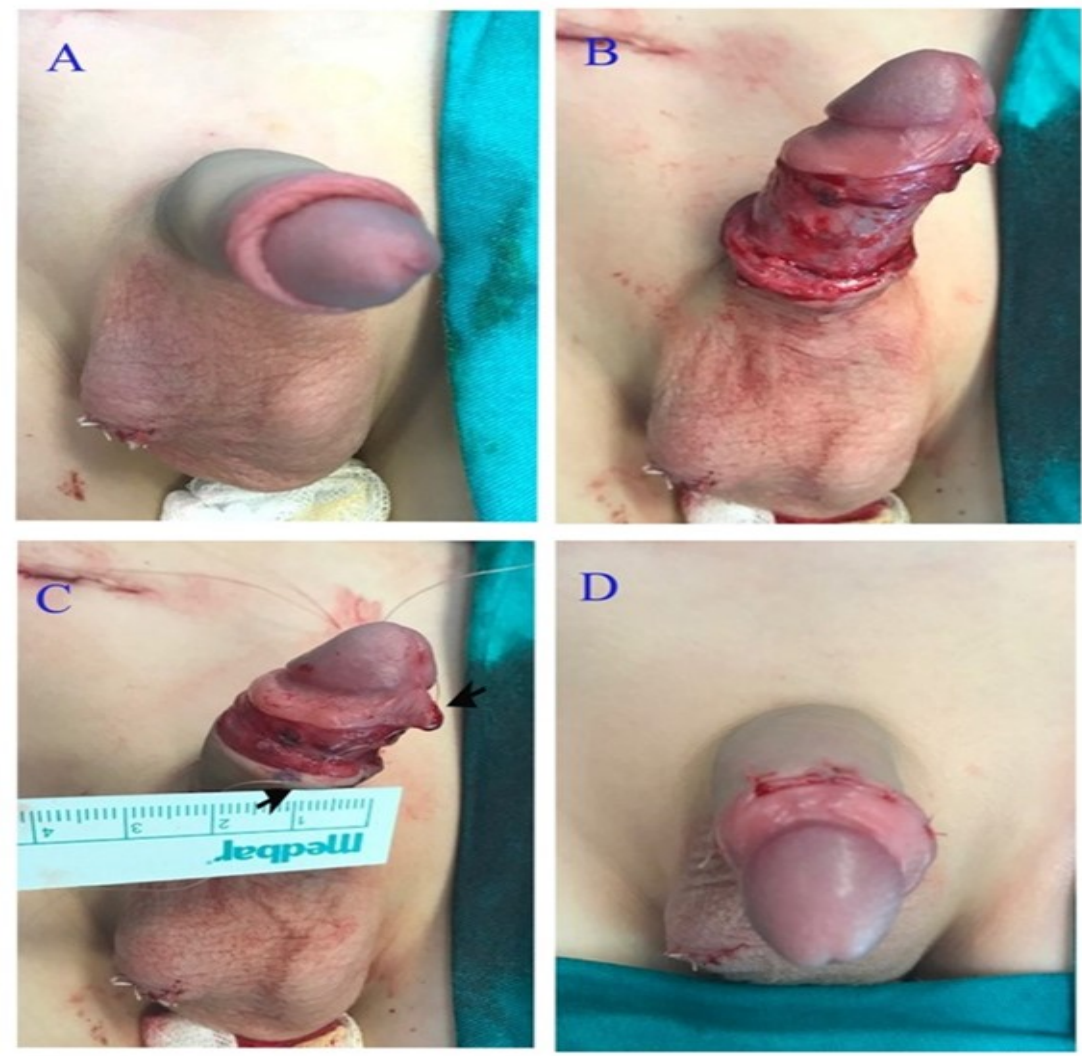

Resim1. A-Penil torsiyon, B-Sünnet ve degloving sonrası kısmi düzelme, C-Frenilum-cilt hizalaması, DAmeliyat sonu görünümü. 
lendirildi.

Istatistik: Çalışmada elde edilen bulgular değerlendirilirken, istatistiksel analizler için IBM SPSS Statistics 22 (IBM SPSS, Türkiye) programı kullanıldı. Çalışma verileri değerlendirilirken tanımlayıc1 istatistiksel metodların (Ortalama, Standart sapma, frekans) yanısıra niceliksel verilerin karşılaştırılmasında Kruskal Wallis testi ve farklılığa neden çıkan grubun tespitinde Mann Whitney U test kullanıldı. Niteliksel verilerin karşılaştırılmasında ise Fisher Freeman Halton testi kullanıldı. Anlaml11ık $\mathrm{p}<0,05$ düzeyinde değerlendirildi.

\section{BULGULAR}

Kliniğimize sünnet istemiyle başvuran 2650 erkek çocuğun \%1,2 $(n=32)$ 'sinde 45 derece ve üzerinde konjenital izole penil torsiyon tespit edildi. Bu hastaların yaş ortalaması $3,09 \pm 2.04$ idi. Torsiyon derecesi \%81,3 $(\mathrm{n}=26)$ hastada 45-90 derece, \%18,7 $(n=6)$ hastada 90-150 derece arasında idi. Penil torsiyon yönü, hastaların \%93,8 $(\mathrm{n}=30)$ 'unda sola (saatin tersi yönüne), \%6,2 $(\mathrm{n}=2)$ ' inde sağa (saat yönünde) idi. Penil torsiyonu olan hastaların \%62,5 $(n=20)$ '1 herhangi bir şikayet tarif etmezken, hastaların \%37,5 $(\mathrm{n}=12)$ 'inde peniste eğrilik şikayeti vardı.. Üç hastada peniste eğrilik şikayetine ek olarak yana işeme şikayeti vardı (Tablo 1). Şikayete göre yaş ortalamaları arasında istatistiksel olarak anlamlı farklılık bulunmaktaydı. $(\mathrm{p}<0,05)$. Penis eğriliği+yana işeme şikayeti olan hastaların yaş ortalaması, şikayeti olmayan ve penis eğriliği şikayeti olan hastaların yaşlarından anlamlı şekilde yüksektir $(p<0,05)$. Şikayeti olmayan hastalar ile penis eğriliği şikayeti olan hastaların yaş ortalamaları arasında istatistiksel olarak anlamlı bir farklılık bulunmamaktadır ( $\mathrm{p}>0,05)$ (Tablo2).

Şikayetlerin varlığı ile torsiyon derecesi arasında istatistiksel olarak anlamlı farklılık görülmektedir $(p<0,05)$. Peniste eğrilik şikayeti, torsiyonun $>90$ derece üzerinde olduğu hastalarda \%100'ünde, 4590 derece torsiyonu olan hastaların \%11,5'i sadece penis eğriliği, $\% 11,5$ ' $i$ ise penis eğriliği+yana işeme şikayeti vard1 (Tablo3).

Komplikasyonlar: Hiçbir hastamizda ek cerrahi prosedüre ihtiyaç duyulmadı. Ameliyattan sonra hastaların \%9 $(n=3)$ 'de herhangi bir tedaviye ihtiyaç duymadan spontan düzelen ekimoz görüldü. Kanama, hematom ve enfeksiyon gibi erken komplikasyon ve ikinci ameliyatı gerektirecek nüks veya rezidü torsiyon görülmedi.

Tablo 1. Hastaların parametrelerinin dağılımı.

\begin{tabular}{|l|l|c|c|}
\hline \multicolumn{2}{|l|}{} & $\mathbf{n}$ & $\mathbf{\%}$ \\
\hline Penil Torsiyon & Var & 32 & 1,2 \\
\cline { 2 - 4 } & Yok & 2618 & 98,8 \\
\cline { 2 - 4 } & Toplam & 2650 & 32 \\
\hline \multirow{5}{*}{ Torsiyon Derecesi } & $45-90$ & 26 & 81,3 \\
\cline { 2 - 4 } & $90-150$ & 6 & 18,7 \\
\cline { 2 - 4 } & Toplam & 32 & 100 \\
\hline Şikayet & Sol & 30 & 93,8 \\
\cline { 2 - 4 } & Săg & 2 & 6,2 \\
\cline { 2 - 4 } & Toplam & 20 & 62,5 \\
\cline { 2 - 4 } & Şikayet yok & 12 & 37.5 \\
\cline { 2 - 4 } & Şikayet var & 9 & 28,1 \\
\cline { 2 - 4 } & Penis eğriliği & 3 & 9,4 \\
\cline { 2 - 4 } & Penis eğriliği+Yana işeme & 32 & 100 \\
\hline Toplam & & & \\
\hline
\end{tabular}

Tablo 2. Penil torsiyonu olan hastaların yaşa göre dağılımı.

\begin{tabular}{|l|c|c|c|}
\hline \multirow{2}{*}{ Şikayet } & \multicolumn{2}{|c|}{ Yaş } & p \\
\cline { 2 - 3 } & Ort \pm SS & Medyan & \multirow{2}{*}{$\mathbf{0 , 0 0 5}^{*}$} \\
\cline { 2 - 3 } Sünnet istemi+şikayet yok & $3,05 \pm 1,67$ & 3 & \\
\cline { 1 - 3 } Sünnet istemi+Penis eğriliği & $1,89 \pm 1,36$ & 1 & \\
\hline Sünnet istemi Penis eğriliği+Yana işeme & $7 \pm 1$ & 7 & \\
\hline Toplam & $3,09 \pm 2,04$ & 2,5 & \\
\hline
\end{tabular}

Kruskal Wallis Test; *:p $<0.05$. 
Tablo 3. Penil torsiyon derecesi-şikayet ilişkisinin değerlendirilmesi.

\begin{tabular}{|c|c|c|c|c|}
\hline \multirow[t]{2}{*}{ Şikayet } & $\begin{array}{c}\text { Torsiyon Derecesi 45- } \\
90\end{array}$ & $\begin{array}{c}\text { Torsiyon Derecesi 90- } \\
150\end{array}$ & Toplam & $\mathbf{P}$ \\
\hline & n (\%) & n (\%) & n (\%) & \multirow{5}{*}{$0,0001 *$} \\
\hline Şikayet yok & $20(\% 76,9)$ & $0(\% 0)$ & $20(\% 62,5)$ & \\
\hline Penis eğriliği şikayeti & $3(\% 11,5)$ & $6(\% 100)$ & $9(\% 28,1)$ & \\
\hline Penis eğriliğ $i+Y$ ana işeme & $3(\% 11,5)$ & $0(\% 0)$ & $3(\% 9,4)$ & \\
\hline Toplam & $26(\% 100)$ & $6(\% 100)$ & $32(\% 100)$ & \\
\hline
\end{tabular}

Fisher Freeman Halton Test; $*: p<0.05$.

\section{TARTIŞMA VE SONUÇ}

Konjenital izole penil torsiyon penis gelişimi sürecinde oluşan şekil bozukluğudur. Penisin embriyolojik gelişimi oldukça karmaşık bir süreçtir. Her üç germ tabakasını da içerir. Genital tüberkülün mezoderm yaprağından; corpus cavernozum, corpus spongiozum, bağ dokusu ve dermis, endodermal kabartıdan; penil üretra, ektodermden glanduler üretra ve eksternal meatus oluşur. Üretral oyuğun ektodermal kısımları ise birleşerek median rafeyi albuginea to the pubic periosteum for correction of penile torsion: a prospective randomize study. oluşturur. Dartos dokusu, genital cildin hemen altında yerleşmiş, penil şafti saran fibromuskuler yapıdır. Penis gelişimi sürecinde penil şaft ile dartos ve cilt arasındaki uyumsuzluğun konjenital penil torsiyona sebep olduğu düşünülmektedir. Raphe rotasyon olan tarafa doğru spiral şeklinde dönmüştür. ${ }^{6-8}$.

Yapılan çalışmalarda izole penil torsiyonun herhangi bir semptoma neden olmadığını, ebeveynlerin ilerde cinsel fonksiyon bozukluğuna sebep olacağı kaygısı ile penil torsiyonu düzeltmek istedikleri belirtilmiş. ${ }^{1,9}$ Ancak bizim çalışmamızda hastaların birinci başvuru sebebi sünnet isteği olmakla birlikte ebeveynlerin \% 37,5 ' $\mathrm{i}$ (45-90 derece hastalarda $\% 23,>90$ derece hastalarda \%100) sünnet kararı verildikten sonra çocukta penis eğriliği olduğunu söyledi ve düzeltilmesini istedi. Ayrıca okul çağındaki üç hastamızın tamamının yana doğru işediğini söylemesi dikkat çekici idi. Ebeveynlerin söylemekten kaçındığ penil eğriliğin ve yana doğru işeme şikayetinin cerrahi düzeltmeyi gerektiren birer semptom olduğunu düşünüyoruz.

Penil torsiyon prevelansı farklı çalışmalarda değişiklikler göstermektedir. Kuzey Hindistanda 5018 yenidoğan üzerinde yapılan çalışmada 30 derecenin üzerindeki izole penil torsiyon prevelansı \%1,97 olarak bildirilmiştir. ${ }^{9}$ Türkiyeden Eroglu E ve Gundogdu $\mathrm{G} ;{ }^{10} 1000$ yenidoğanda yaptıkları çalışmada izole penil torsiyon oranını $\% 20$, cerrahi düzeltme gereken orta ve ileri derece torsiyon oranın ise $\% 2,15$ olarak bildirmişler. Hamed M. El Darawany ve ark. ${ }^{4}$ sünnet için başvuran, yaşları 2 hafta-6 yaş arasındaki 1650 hastada $\% 31,2$ oraninda penil torsiyon tespit etmiş. Bu çalışmada da vakaların sadece \%3,7'si 45 derecenin üstündeki torsiyonlardır. Görüldüğü gibi yapılan çalışmalarda penil torsiyon oranları farklı ve yüksek olmasına rağmen cerrahi düzeltme gerektiren orta ve ileri derece torsiyonlar çok daha azdır.

Çalışmamızda sünnet istemi ile başvuran 2650 hastanın \%1,2 ( $\mathrm{n}=32)$ 'inde $>45$ derece konjenital izole penil torsiyon tespit ettik. Penil torsiyon oranımızın diğer çalışmalardan düşük olmasının sebebi hastalarımızın yaş ortalamasının daha büyük olması olabilir. Çünkü penis doğumdan sonra da gelişmeye devam eder ve yaş ile birlikte fimozisin açılması penil torsiyonun kismen gerilemesine sebep olabilir. Çalışmamızda $>45$ derecenin üstündeki torsiyonların $\% 81,3$ nin orta (45-90), \%18,7 nin ileri derece (>90) olması ve penil torsiyonun yönünün $\% 93,8$ sol tarafa, $\% 6,2$ sağ tarafa olması literatür ile benzer idi. Penil torsiyonların düzeltilmesi için çok sayıda cerrahi teknik kullanılmaktadır. Hafif konjenital izole penil torsiyonların düzeltilmesi için sünnet ve basit cilt hizalamasının yeterli olduğu, fakat orta ve ileri derece torsiyonlar ile ek anomalilerin eşlik ettiği torsiyonlar için cerrahi düzeltme gerektiği konusunda cerrahlar arasında fikir birliği vardır. ${ }^{10-12}$ Ancak ideal cerrahi yöntem konusunda fikir birliği yoktur. Uygulanan cerrahi yöntem ne kadar kompleks ise komplikasyon gelişme oranı o kadar yüksek olur. Aldaqadossi ve ark. $^{13}$ konjenital penil torsiyon onarımında karşılaştırdığı, dorsal dartos flebi tekniği ile tunica albugineayı pubic periostuma suture ederek onardığı torsion düzeltme sonuçlarının benzer olduğunu, dorsal dartos flebinin daha kolay ve komplikasyonların daha az olduğunu bildirmiştir. Son yıllarda izole penil torsiyon onarımı için basit ve uygulama kolaylığı nedeniyle degloving ve yeniden cilt hizalama yöntemi tercih edilmektedir. ${ }^{9,10} \mathrm{Bu}$ teknikte penoskrotal seviyeye kadar yapılan degloving penil şaft ile cilt arasındaki bağlantının kesilmesini sağlar. Penil şaftın ciltten ayrılması ile penil torsiyon kısmen düzelir, kalan torsiyon yeniden hizalama ile düzeltilebilir. Ancak torsiyon derecesi fazla olan hastalarda yeniden hizalama yaparken rapheyi orta hata getirmek zordur. Rapheyi orta hata getirmeye çalışmak laterale konumlanmış raphe ve cildin penil şaft1 tekrar torsiyone etmesine sebep olur. Bunun için özellikle ileri derece torsiyonlarda 
ek cerrahi işlem veya daha invazif yöntemlere başvurulmaktadır. ${ }^{5,14,15}$ El Darawany ve ark. ${ }^{4} 45$ derecenin üzerinde izole penil torsionu olan 62 hastadan 21 'inde degloving ve cildin yeniden hizalamas1, diğer 41 hastada ise degloving ve cildin aşırı çekiştirilmesi veya dartos flebi gibi farklı teknikler kullanmıș.

Marret ve ark. ${ }^{16}$ ise yaptıkları çalışmada 45-90 derece arasındaki torsiyonların \%75'inde degloving-cilt hizalamasi ile düzeltebilirken $\% 25$ 'inde dartos flebine ihtiyaç duymuş, 90 dereceden fazla torsiyonu olan hastaların ise \%86'sında torsiyonu düzeltmek için dartos flebine ihtiyaç duymuş ve dartos flep prosedürüne duyulan ihtiyacin torsiyon derecesi ile doğru orantılı olduğunu bellirtmişler.

Çalışmamızda orta ve ileri derece tüm penil torsiyonlarda diğer çalışmalarda olduğu gibi penoskrotal seviyeye kadar degloving yaptık, penil şaftı ciltten ay1rarak serbestleştirdik. Degloving ile serbestleşen ve kısmen düzelen torsiyonu rapheyi konumlandığı yerde birakarak kolayca düzeltebildik. Rapheyi orta hata getirmek için zorlamadık. Torsiyonu düzeltmek için hiçbir hastamızda ek cerrahi işleme veya daha invazif bir tekniğe ihtiyaç duymadık. Bu da hem uygulama kolaylığı hem de ameliyat süresinin daha kısa olmasını sağladı. Ameliyat sonrası hastaların \%9,3 $(n=3)$ 'ünda kendiliğinden düzelen ekimoz görüldü. Hiçbir hastamızda hematom, kanama gibi erken komplikasyon ve takibinde rezidü torsiyon görülmedi. Tüm hastalarda eksternal üretral mea görünümü ve işeme yönü düzgündü. Penis görünümü raphe çizgisinin laterale doğru seyretmesi dışında tamamen normaldı. Penis görünümü hekim ve ebeveynler için tatminkardi.

Sonuç olarak; torsiyon derecesi $>45$ derece olan konjenital izole penil torsiyon prevalans1 \%1,2 (45-90 derece $\% 1,>90$ derece $\% 0,2$ ) oranında görülmektedir. Raphe mevcut konumda birakilarak uygulandığında güvenli ve basit bir yöntem olan deglovingcilt hizalaması yöntemi ile tüm konjenital izole penil torsiyonların düzeltilebilir. Ayrıca orta ve ileri derece penil torsiyonu olan hastalarda yana işemeve penil eğrilik şikayetinincerrahi düzeltme endikasyonu olduğunu düşünüyoruz.

Etik Komite Onayı: Bu araştırma Sağlık Bilimleri Üniversitesi Tıp Fakültesi Ümraniye Eğitim Araştırma Hastanesi Girişimsel Olmayan Klinik Araştırmalar Etik Kurulu tarafindan onaylanmıştır (Tarih: 20.11.2019, karar no:24428).

Çıkar Çatışması: Yazarlar çıkar çatışması bildirmemişlerdir.

Yazar Katkıları: Fikir - MA; Denetleme -CŞ, Zİ; Malzemeler - MA,SLM; Veri toplanması ve/veya işlemesi MA,HNKA; Analiz ve/veya yorum -MA, ZI; Yazıyı yazan - MA,HNKA.

Hakem Değerlendirmesi: Dış bağımsız.

\section{KAYNAKLAR}

1. Castagnetti M, Leonard M, Guerra L, Esposito C, Cimador M. Benign penile skin anomalies in children: A primer for pediatricians. World J Pediatr. 2015;11(4)316-323. doi:10.1007/s12519. 015-0015-5

2. Bıçakçı Ü, Issı Y, Yağız B, Demirel BD. Evaluation the outcome of two-stage repair in children with proximal hypospadias and severe chordee with hypospadias objective penile evaluation (HOPE) scoring. J Contemp Med. 2019;9(4):373377. doi: $10.16899 / \mathrm{jcm} .561241$

3. Kestel M, Tarhan H, Şahin H. Male Circumcision. Medical Journal of Mugla Sitki Kocman University. 2018;5(1):27-31.

4. El Darawany HM, Al Damhogy ME, Kandil MS, Elkordi ME, Nagla SA, Taha MR. Procedures used for correction of isolated penile torsion: are they competitive or complementary? Int. Urol Nephrol. 2019;51(8):1313-1319. doi:10.1007/ s11255-019-02163-9

5. Elbakry A, Zakaria A, Matar A, El Nashar A. The management of moderate and severe congenital penile torsion associated with hypospadias: Urethral mobilisation is not a panacea against torsion. Arab J Urol. 2013;11(1):1-7. doi:10.1016/j.aju.2012.12.004

6. Pişkin MM, Yılmaz K. Embrryology and developmental mechanisms of the male urogenital system (penis and urethra). Turk Urol Sem. 2011;2:170-172.

7. Cunha GR, Baskin LS. Development of the external genitalia. Differentiation. 2020;112:7-9. doi:10.1016/j.diff.2019.10.008

8. Jordan G, McCammon K. Surgery of the penis and urethra, Urology $\left(10^{\text {th }}\right.$ edition $)$, Walsh C, Philadelphia, USA; 2012:177-189.

9. Bhat A, Bhat M, Kumar V, Goyal S, Bhat A, Patni $M$. The incidence of isolated penile torsion in North India: A study of 5,018 neonates. J Pediatr Urol. 2017;13(5):491.e1-491.e6. doi:10.1016/ j.jpurol.12.031

10. Eroglu E, Gundogdu G. Isolated penile torsion in newborns. Can Urol Assoc J. 2015;9(11-12):805807. doi:10.5489/cuaj.2833

11. Fisher PC, Park JM. Penile torsion repair using dorsal dartos flap rotation. J Urol. 2004;171 (5):1903-1904. doi:10.1097/01.ju.0000120148.79867.5c

12. Aykaç A, Baran Ö, Yapıcı O, Aygün BA, Aydın C, Çakan M. Penil degloving and dorsal dartos flap rotation approach for the management of isolated penile torsion. Turk J Urol. 2016;42 (1):27-31.

13. Aldaqadossi HA, Elgamal SA, Seif Elnasr MK. Dorsal dartos flap rotation versus suturing tunica J Pediatr Urol. 2013;9(5)643-647. doi:10.1016/ 
j.jpurol.2012.07.014

14. Elbatarny AM, İsmail KA. Penile torsion repair in children following a ladder step: simple steps are usually sufficient. J Pediatr Urol. 2014;10 (6):1187-1192. doi:10.1016/j.jpurol.2014.05.009

15. Bhat A, Sabharwal K, Bhat M, Singla M, Kumar V, Upadhyay R. Correction of penile torsion and chordee by mobilization of urethra with spongiosium in chordiee without hipospadias. J Pediatr Urol. 2014;10(6)1238-1243. doi:10.1016/ j.jpurol.2014.06.016

16. Marret JB, Ravasse P, Raffoul L, Rod J. The Fisher Technique for correction of penile torsion in children: Who are the candidates? Urology. 2017;104(6):179-182. doi:10.1016/

j.urology.2017.02.038 